\title{
THE ORIGIN OF RADIATE SENECIO VULGARIS L.
}

\author{
C. A. STACE \\ Botanical Laboratories, University of Leicester, Leicester LEI 7RH, England
}

Received 14.iii.77

\section{SUMmary}

Over the past 20 years there has been a rapid spread in the British Isles of the radiate variant of Senecio vulgaris $\mathrm{L}$. The evidence that this variant has arisen (a) from introgression into $S$. vulgaris by $S$. squalidus, or $(b)$ as a mutant of $S$. vulgaris, is summarised. It is concluded that the latter alternative seems at least equally plausible judging from the available data, and that there appears to be no reason to believe that the spread of radiate groundsel is a measure of continuing hybridisation.

\section{Historical BaGkground}

THE recent extensive spread in the British Isles of the common groundsel (Senecio vulgaris L.) with conspicuous ray-florets (var. hibernicus Syme) is a remarkable illustration of "Evolution in action". Nevertheless, while it has prompted several workers to investigate and write on the subject, the available evidence is still quite insufficient to give a clear answer to the problems this spread poses. Virtually all recent workers (cf. Benoit et al., 1975 ) have concluded or assumed that radiate $S$. vulgaris, which like the typical plant is tetraploid $(2 n=40)$, has originated from repeated introgression into $S$. vulgaris by the diploid $S$. squalidus L. $(2 n=20)$. The latter is a $\mathrm{S}$. European plant which is now widely and often commonly naturalised in the British Isles; its spread here since its first detection outside a garden in 1974 has been carefully documented in a series of papers by Kent (1956, $1957,1960,1963,1964 a, 1964 b, 1964 c, 1964 d, 1966)$. This note attempts to demonstrate that the evidence for the participation of S. squalidus in the increase of radiate $S$. vulgaris is very tenuous, and that the alternative hypothesis, the spread of a mutant of $S$. vulgaris, is at least as likely judging from the available data.

S. vulgaris var. hibernicus has occurred in the British Isles at least since 1866 (Syme, 1875), when it was found in Cork, Eire, but it did not become frequent until the 1930's and it has been common only for the past 20 years or so; it is apparently still rare elsewhere in Europe. It was first seriously studied by Trow (see Trow, 1916), who showed that radiate florets are inherited as a single incompletely dominant gene, a system he designated as $R R / R r / r r . \quad R r$ heterozygotes have much smaller ray-florets than $R R$ plants, although the expression of this character in the heterozygotes is very variable. The expected simple Mendelian ratios have been demonstrated by many subsequent workers; at Leicester stocks of all three phenotypes are continually renewed by sowing achenes from $R r$ plants, which give approximately the expected $1: 2: 1$ ratio. Trow recognised about 12 biotypes of $S$. vulgaris, only one of which he found in the wild to exist as either radiate or non-radiate. He also demonstrated that out-crossing in $S$. vulgaris was usually of the order of 1 per cent, a figure since confirmed 
by Hull (1974a), although Campbell and Abbott (1976) obtained a mean value of 22.4 per cent in artificially randomised plots in open conditions. Gibbs et al. (1975) found that $S$. vulgaris produced 71-75 per cent and $S$. squalidus $4 \cdot 1$ per cent seed-set in the absence of any pollinators.

Hybrids between $S$. squalidus and $S$. vulgaris were first detected by Druce (1886), who later (Druce, 1893) named them S. x baxteri; this name, however, is invalid, being a nomen nudum. Although experienced field botanists have little trouble in distinguishing these hybrids from radiate $S$. vulgaris (cf. Brenan, 1948), they have been greatly over-recorded by such misidentifications in the past, and still are so, and the existence of another radiate variant of $S$. vulgaris in this country, var. denticulatus (O. F. Muell.) Hyland. (Allen, 1967), has further complicated the situation. The latter plant is, however, quite different from var. hibernicus and occurs on maritime dunes. Hybrids are very infrequent and limited to areas where the two parents co-exist in some abundance, usually over several years, and they arc usually only of annual duration.

Rosscr (1955) described a new hexaploid species, S. cambrensis, which she supposed was the alloploid derivative of $S$. squalidus $\times S$. vulgaris, itself presumably triploid (although not before now so reported in wild material). $S$. cambrensis was described from material from near Ffrith, Flintshire, where it was first detected in 1948 by H. E. Green and where it still occurs. It has spread little since then, although it has recently been reported about $40 \mathrm{~km}$ north-west at Colwyn Bay, Denbighshire.

Haskell (1953) suggested that radiate $S$. vulgaris is an ecospecies adapted to the warmer, wetter areas of western Britain, but he failed to distinguish betwcen var. denticulatus and var. hibernicus.

\section{THE EVIDENCE FOR A HYBRID ORIGIN}

Later workers (Crisp and Jones, 1970; Hull, 1974a, 1974b, 1975, 1976; Richards, 1975; Monaghan and Hull, 1976) have presented data which they have considered circumstantial evidence for the origin of radiate $S$. vulgaris by introgression from $S$. squalidus. This evidence may be summarised as follows:

1. The spread of radiate $S$. vulgaris has broadly followed that of $S$. squalidus in this country. Early workers such as Druce (1886) and Trow (1912) remarked that radiate $S$. vulgaris often occurred together with $S$. squalidus, although neither suggested any closer connection and Trow concluded that "These two species appear to have no necessary association with each othcr". On the other hand there was considerable disagreement concerning the origin, hybridogenous or otherwise, of the original radiate S. vulgaris from Cork (Morc, 1898), and Drucc (1886) suggcsted that the variation of $S$. squalidus could be attributed to hybridisation with $S$. vulgaris.

2 . It is claimed that at least some strains of radiate $S$. vulgaris more closely resemble $S$. squalidus than does non-radiate $S$. vulgaris. Characters cited have been the growth-rate (Richards, 1975), leaf length and breadth (Monaghan and Hull, 1976) and esterase isozymes (Hull, 1974b).

3. Although $S$. squalidus $\times S$. vulgaris is normally highly sterile, Crisp and Jones (1970) reported a plant " closely resembling Rosser's $S$. cambrensis" whose selfed progeny segregated for $S$. squalidus and $S$. vulgaris characters and were all fertile tetraploids. Moreover, they claimed that $S$. cambrensis, 
which normally behaves as a completely stable amphidiploid, at least in cultivation (cf. plants grown at Cambridge, Leicester and Manchester), has segregated in its native area, where a pure-breeding, non-radiate variant exists, and that $S$. cambrensis " appears from the herbarium records to have arisen in Wales at least 40 years ago" (i.e. about 1930, 18 years before its discovery by H. E. Green). Harland (1954) and Gibbs (1971) both obtained experimental $S$. squalidus $\times S$. vulgaris plants. Harland found they were sterile triploids and, by colchicine treatment, produced from them hexaploid, fertile plants resembling $S$. cambrensis. Crisp and Jones have not reported finding wild triploids or synthesising artificial ones.

\section{The evidence Against A Hybrid ORIGiN}

In the arguments used in the post-1970 papers cited above, the evidence for the possible role of introgression has been emphasised at the expense of that against it. It is therefore important that prominence be given to the latter.

1. The parallel spread of $S$. squalidus and radiate $S$. vulgaris, while quite close in some areas, especially those which have been colonised rather recently, is not apparent in many other areas. In the London area, for example, S. squalidus arrived just after 1900 and was abundant in many areas by 1940 , yet up to 1952 radiate $S$. vulgaris had been recorded on only six occasions (Kent and Lousley, 1953). Elsewhere in south-eastern England $S$. squalidus was common in many areas by 1950 , but in 25 years of planthunting in the area $I$ have seen radiate $S$. vulgaris there only once and it is said by others to be still uncommon. Moreover, it is rare or absent over the large areas of S. Europe where $S$. squalidus is native. In fact in Britain the rapid spread of radiate $S$. vulgaris has taken place over the past 20 years irrespective of the date of arrival of $S$. squalidus, and it seems at least equally reasonable to consider that its coincidence with the latter is a measure of its preference for similar habitats.

2. The evidence for the greater resemblance of radiate than non-radiate $S$. vulgaris to $S$. squalidus is all equivocal. Richards (1975) found this was so for the growth-rate of British plants, but his non-radiate plants from Jugoslavia resembled radiate rather than non-radiate British $S$. vulgaris in this respect. The leaf characters used by Monaghan and Hull (1976) are not good discriminants between $S$. vulgaris and $S$. squalidus. There is such great variation in leaf characters of both species, especially leaf-dissection, that an approach along these lines is unlikely to be profitable. Hull's (1974b) esterase isozyme patterns showed "some evidence that radiate individuals of $S$. vulgaris . . . were more like $S$. squalidus than were nonradiate individuals", but there was in fact " no significant difference between radiate and non-radiate plants" from the same area. The great range of variation shown by $S$. vulgaris is best exhibited in waste places, where it is likely to have originated from several sources and where $S$. squalidus is also often present. In cultivated ground $S$. vulgaris is more constant, and radiate plants and $S$. squalidus are usually absent.

Although the two species are superficially quite different, quantitative differences are extremely difficult to define. Brenan (1948) pointed out a difference in the stigma-lobes, which have a well-marked tuft of long papillae in $S$. squalidus but which are smooth or have short or sparse papillae in $S$. 
vulgaris. In this respect, as well as in all others (notably leaf-characters) apart from the presence of ray-florets, radiate $S$. vulgaris seems identical with non-radiate $S$. vulgaris, as was remarked by Richards (1975).

3. The ray-florets of $S$. vulgaris seem certainly to be controlled by a single gene, albeit showing incomplete dominance and a variable expression when heterozygous. If this character has entered $S$. vulgaris from $S$. squalidus, at least some plants of $S$. vulgaris which we today describe as having $R R$ genotypes would in fact be heterozygous and would not be expected to behave in the simple Mendelian pattern observed. Moreover, the ray-florets of $S$. vulgaris differ significantly from those of $S$. squalidus in appearance.

An equally plausible explanation appears to be that radiate $S$. vulgaris originated as a mutation which, in view of the normally radiate character of all species closely related to $S$. vulgaris, could be considered a backmutation. Mutations of members of the Asteraceae from a radiate to a non-radiate state, and vice versa, are very common. Aster tripolium L. and Leucanthemum vulgare Lam. are well-known examples of the first direction, Bidens cernua L. of the oppositc. In Senecio, S. jacobaea L. (Harper \& Wood, 1957; Meijden, 1976) and S. squalidus (personal obscrvation) are known as non-radiate variants, and $S$. vulgaris exists as the radiate var. denticulatus, a distinctive plant with a characteristic ecology and pattern of distribution (Allen, 1967).

4. True $\mathrm{F}_{1}$ hybrids between $S$. squalidus and $S$. vulgaris are rare and highly (if not fully) sterile, and seem unlikely to be able to account for the rapid spread of radiate $S$. vulgaris. After such searching over many years I have found only four plants; three in three different years near Manchester University and one near Leicester railway station; all on waste ground in large mixed populations of $S$. squalidus and $S$. vulgaris which had persisted for several years. At Manchester, radiate $S$. vulgaris is very common, but at the Leicester site I have not encountered it. Chromosome counts of the Manchester and of the Leicester hybrid were both triploid, $2 n=30$, as expccted. The plants were all apparently totally sterile; no $F_{2}$ plants were obtained from hundrcds of achenes sown. Neither Harland (1954) nor Gibbs (1971) commented sufficiently on the fertility of their artificial hybrids, although Gibbs stated that he could obtain no $\mathrm{F}_{2}$ plants.

Presumed $F_{1}$ hybrids are intermediate between their two parents, as can be seen by comparing them with the parental species growing in the same locality. They differ conspicuously in the field from radiate $S$. vulgaris in their greatcr stature and in leaf and flower characters. Indced, Stephcnson (1946) was confident in recording the hybrid $S$. squalidus $\times S$. vulgaris var. hibernicus.

5. The only published evidence for the existencc of plants which could be interprcted as early stages of introgression frorn $S$. squalidus to $S$. vulgaris is the fertile plant found in 1966 by Crisp and Jones (1970) in east London. Although its segregating progeny were studied in some detail, the chromosome number and hence the progenitors of the plant were not known. If the postulated origin of a plant such as this could be confirmed, and if plants identical with $S$. vulgaris var. hibernicus could bc obtained in its segregating progeny, then at least the feasibility of the introgression of $S$. squalidus into $S$. vulgaris would have been demonstrated. So far, however, neither of these requirements have been reported to have been fulfilled.

The most obvious routes of possible introgression would be via sterile 
triploid $F_{1}$ plants, or via fertile tetrapoloid hybrid plants resulting from the production of diploid gametes by $S$. squalidus, either from autotetraploid or (by non-reduction) from normal diploid plants. The rarity and sterility of triploids mitigates against the former possibility, while offspring resulting from the fusion of diploid gametes from each species would presumably be closer in appearance to $S$. squalidus (not to $S$. vulgaris) than would triploid plants.

Harland (1954) had the intention of repeatedly backcrossing his artificial triploid hybrid to $S$. vulgaris in an attempt to generate radiate $S$. vulgaris, but no results were ever published. Gibbs (1971) was able to backcross his artificial hybrid to $S$. squalidus, though not to $S$. vulgaris and he could not obtain an $\mathrm{F}_{2}$.

\section{Conclusion}

The hybridogenous origin of $S$. vulgaris var. hibernicus is a plausible hypothesis, but as yet there is only rather weak circumstantial evidence to support it. Since mutation of radiate to non-radiate and non-radiate to radiate variants of a range of species of Asteraceae is well known, including examples in the genus Senecio, the alternative hypothesis of a mutation seems at present equally likely.

Whatever its mode of origin, all the available data are consistent with the view that radiate $S$. vulgaris seldom originates de novo, but rather that its recent rapid spread is mostly the result of its dispersal to and colonisation of new localities. There thus appears to be no reason to postulate "continuing interspecific hybridisation" as has been claimed. Increase in the frequency of a gene governing radiate/non-radiate capitula is also shown by non-radiate Aster tripolium L. (var. discoideus Reichenb. fil.), which has greatly increased in frequency on the eastern coast of England since the 1930 's, but which for the past ten years seems to have been in a state of balanced polymorphism (A. J. Gray, personal communication, 1977). The genetics of ray-florets in Aster is far more complex than in Senecio, and in the former case there is no related species from which non-radiate capitula could have been obtained, but there may be ecological parallels in the two cases and, indeed, Hull's (1976) data indicate a marked falling off in the increase of radiate $S$. vulgaris for 1973-74 compared with that for 1972-73.

\section{REFERENCES}

ALLEN, D. E. 1967. The taxonomy and nomenclature of the radiate variants of Senecio vulgaris L. Watsonia, 6, 280-282.

BENOIT, P. M., GRISP, P. C., AND JONES, B. M. G. 1975. Senecio L. In Hybridization and the Flora of the British Isles, C. A. Stace ed. Academic Press, London, New York and San Francisco.

BRenan, J. P. M. 1948. Senecio squalidus L. $\times$ vulgaris L. Rep. botl Soc. Exch. Club Br. Isl., 13,364 .

CAMPBELL, J. M., AND ABBOTT, R. J. 1976. Variability of outcrossing frequency in Senecio vulgaris L. Heredity, 36, 267-274.

GRISP, P. C., AND JONES, B. M. G. 1970. Senecio squalidus L., S. vulgaris L. and S. cambrensis Rosser. Watsonia, 8, 47-48.

DRUCE, G. G. 1886. The Flora of Oxfordshire, pp. 449-450. Parker, Oxford and London. DRUGE, G. G. 1893. Senecio vulgaris $\times$ squalidus. Rep. botl Soc. Exch. Club Br. Isl., 1, 374.

Gribs, P. E. 1971. Studies on synthetic hybrids of British species of Senecio, 1. Senecio viscosus L. $\times$ S. vulgaris L. Trans. bot. Soc. Edinb., 41, 213-218. 
GibBs, P. E., Milne, C.; AND GARRillo, M. 1975. Corrclation between the breeding system and rccombination index in five species of Senecio. Neze Phytol., 75, 619-627.

haRland, s. c. 1954. The genus Senecio as a subject for cytogenetical investigation. Proc. bot. Soc. Br. Isl., 1, 256-257.

HARPER, J. L., AND wOoD, w. A. 1957. Senecio jacobaea L., in Biological Flora of the British Isles. 7. Ecol., 45, 617-637.

haskell, G. 1953. Adaptation and the brecding system in groundsel. Genetica, 26, 468-484. HULl, P. 1974a. Self-fcrtilization and the distribution of the radiate form of Senecio vulgaris L. in central Scotland. Watsonia, 10,69-75.

HULL, P. 1974b. Differences in esterase distribution detected by electrophoresis as evidencc of continuing interspecific hybridisation in the genus Senecio. Ann. Bot., n.s., 38, 697-700.

HULt, P. 1975. Selection and hybridisation as possible causes of changes in the frequency of alleles controlling capitulum-type in Senecio vulgaris L. Watsonia, 10, 395-402.

HULL, $P$. 1976. The influences of different degrees of interspecific hybridisation with Senecio squalidus on the frequency of two morphs of Senecio vulgaris. Heredity, 36, 67-72.

KENT, D. H. 1956. Senecio squalidus L. in the British Isles, 1. Early records (to 1877). Proc. bot. Soc. Br. Isl., 2, 115-118.

кEnT, D. H. 1957. Senecio squalidus L. in the British Isles, 3. East Anglia. Trans. Norf. Norw. Nat. Soc., 18(5), 30-31.

KENT, D. H. 1960. Senecio squalidus L. in the British Isles, 2. The spread from Oxford (1879-1939). Proc. bot. Soc. Br. Isl., 3, 375-379.

Kent, D. II. 1963. Senecio squalidus L. in the British Isles, 7. Walcs. Nature Wales, 8, 175-178.

KEnt, D. H. 1964a. Senecio squalidus L. in the British Isles, 4. Southcrn England (1940 $\rightarrow$ ). Proc. bot. Soc. Br. Isl., 5, 210-213.

KENT, D. H. 1964b. Senecio squalidus L. in the British Isles, 5. The Midlands $(1940 \rightarrow)$. Proc. bot. Soc. Br. Isl., 5, 214-216.

KENT, D. H. 1964c. Senecio squalidus L. in the British Isles, 6. Northern England $(1940 \rightarrow)$. Proc. bot. Soc. Br. Isl., 5, 217-219.

KENT, D. H. 1964d. Senecio squalidus L. in the British Isles, 9. Ireland. Irish Nat. J., 14, 203-204.

KENT, D. H. 1966. Senecio squalidus L. in the British Isles, 8. The reccnt spread in Scotland. Glasg. Nat., 18, 407-408.

Kent, D. H., AND Louslex, J. E. 1953. Senecio L., in A hand list of the plants of the London area. Lond. Nat., 32, suppl., 158-161.

MTIJDEN, R. VAN DER. 1976. Het verspreidingsgebied van Senecio jacobaea L. var. nudus Weston. Gorteria, 8, 57-61.

MONAGHAN, J. L., AND hULL, P. 1976. Differences in vegetative charactcristics among four populations of Senecio vulgaris L. possibly due to interspecific hybridisation. Ann. Bot., n.s., 40, 125-128.

MORE, A. G. 1898. Contributions Towards a Cybele Hibernica, 2 nd ed. by N. Colgan and R. W. Scully, p. 187. Ponsonby, Dublin.

RIGHARDS, A. J. 1975. The inheritance and behaviour of the rayed gene complex in Senecio vulgaris. Heredity, 34, 95-104.

Rosser, E. M. 1955. A new British specics of Senecio. Watsonia, 3, 228-232.

StePHENSON, T. 1946. A new Senecio hybrid. Naturalist, Hull, 819, 137-138.

syme, J. T. B. 1875. Senecio vulgaris L. var. hibernica mihi. Botl Exch. Club, Rep. Curators, $1872-74,27-28$.

rRow, A. H. 1912. On the inheritance of ccrtain characters in the common groundselSenecio vulgaris, Linn.-and its segregates. 7. Genet., 2, 239-276.

Trow, A. H. 1916. On the number of nodes and their distribution along the main axis in Senecio vulgaris and its segregates. 7. Genet., 6, 1-63.

Note added in proof. The papers by Oxford and Andrews (Heredity, 38, 367-371, 1977) and Ingram (Heredity, 39, 171-173, 1977) appeared after this paper was submitted for publication. Oxford and Andrews showed that radiate plants produce more capitula per plant and more achenes per capitulum than non-radiate plants, and concluded, like the present author, that this, and not "continuing interspecific hybridisation", is the cause of the rccent spread of radiatc plants. Ingram reported the synthesis of the artificial triploid hybrid S. squalidus $\times S$. vulgaris var. hibernicus (" $f$. radialus"); it was totally sterile with 7 10 univalents at meiosis. She was unable to make the cross using non-radiate $S$. vulgaris, and suggested that this cross is less "easily formed". 